\title{
Pt clusters in BaKL zeolite : characterization by transmission electron microscopy, hydrogen chemisorption, and X-ray absorption spectroscopy
}

\author{
Citation for published version (APA): \\ Vaarkamp, M., Grondelle, van, J., Miller, J. T., Sajkowski, D. J., Modica, F. S., Lane, G. S., Gates, B. C., \& \\ Koningsberger, D. C. (1990). Pt clusters in BaKL zeolite : characterization by transmission electron microscopy, \\ hydrogen chemisorption, and X-ray absorption spectroscopy. Catalysis Letters, 6(3-6), 369-381. \\ https://doi.org/10.1007/BF00764004
}

DOI:

10.1007/BF00764004

Document status and date:

Published: 01/01/1990

\section{Document Version:}

Publisher's PDF, also known as Version of Record (includes final page, issue and volume numbers)

\section{Please check the document version of this publication:}

- A submitted manuscript is the version of the article upon submission and before peer-review. There can be important differences between the submitted version and the official published version of record. People interested in the research are advised to contact the author for the final version of the publication, or visit the $\mathrm{DOI}$ to the publisher's website.

- The final author version and the galley proof are versions of the publication after peer review.

- The final published version features the final layout of the paper including the volume, issue and page numbers.

Link to publication

\footnotetext{
General rights

- You may freely distribute the URL identifying the publication in the public portal. follow below link for the End User Agreement:

www.tue.nl/taverne

Take down policy

If you believe that this document breaches copyright please contact us at:

openaccess@tue.nl

providing details and we will investigate your claim.
}

Copyright and moral rights for the publications made accessible in the public portal are retained by the authors and/or other copyright owners and it is a condition of accessing publications that users recognise and abide by the legal requirements associated with these rights.

- Users may download and print one copy of any publication from the public portal for the purpose of private study or research.

- You may not further distribute the material or use it for any profit-making activity or commercial gain

If the publication is distributed under the terms of Article 25fa of the Dutch Copyright Act, indicated by the "Taverne" license above, please 


\title{
Pt CLUSTERS IN BaKL ZEOLITE: CHARACTERIZATION BY TRANSMISSION ELECTRON MICROSCOPY, HYDROGEN CHIEMISORPTION, AND X-RAY ABSORPTION SPECTROSCOPY
}

\author{
M. VAARKAMP ${ }^{3}$, J.V. GRONDELLE ${ }^{3}$, J.T. MILLER ${ }^{1}$, D.J. SAJKOWSKI ${ }^{1}$, \\ F.S. MODICA ${ }^{1}$, G.S. LANE ${ }^{1}$, B.C. GATES ${ }^{2}$ and D.C. KONINGSBERGER ${ }^{3 *}$ \\ ${ }_{1}^{1}$ Annoco Oil Company, Research Center, P.O. Box 400, Naperville, IL 60540, U.S.A. \\ ${ }^{2}$ Center for Catalytic Science and Technology, Dept. of Chemical Engineering, University of Delaware, \\ Newark, DE 19716, U.S.A. \\ ${ }^{3}$ Laboratory for Inorganic Chemistry and Catalysis, Eindhoven University of Technology, \\ P.O. Box 513, 5600 MB Eindhoven, The Netherlands
}

Received 28 June 1990; accepted 10 September 1990

Zeolite L, platinum, hexane to benzene, EXAFS, TEM

\begin{abstract}
Platinum supported on BaKL zeolite was characterized by Transmission Electron Microscopy (TEM), hydrogen chemisorption, and Extended X-ray Absorption Fine Structure (EXAFS) spectroscopy. The results of all three techniques indicate the presence of highly dispersed platinum in the zeolite pores. There is no evidence of platinum outside the zeolite pores. The EXAFS data determine a Pt-Pt coordination number of 3.7, suggesting that the average platinum cluster in the zeolite consists of 5 or 6 atoms, consistent with the TEM and chemisorption data. The EXAFS data also provide evidence of the platinum-zeolite interface, indicated by Pt-O contributions at 2.14 and $2.70 \AA$, and a Pt-Ba contribution at $3.8 \AA$. The $\mathrm{Pt} / \mathrm{BaKL}$ zeolite is one of the most highly dispersed supported platinum samples and one of the most structurally uniform supported metal catalysts.
\end{abstract}

\section{Introduction}

Platinum supported on L zeolite has been found to be a highly active and selective catalyst for dehydrocyclization of straight-chain paraffins, giving high yields of benzene from $n$-hexane [1-3]. Characterization of these catalysts by techniques including infrared spectroscopy with adsorbed CO [4] and transmission electron microscopy [3] gives evidence that small platinum clusters are incorporated within the intracrystalline pores of the zeolite. Varying fractions of the platinum have also been found outside of these pores in most of the reported catalysts; an exception is that of Rice et al. [5], who used dark-field microscopy to

* To whom correspondence should be sent.

(C) J.C. Baltzer A.G. Scientific Publishing Company 
image the clusters in the pores. The reported work raises fundamental questions about the size and electronic structure of the metal clusters, the nature of the metal-zeolite interactions, and the origin of the catalytic selectivity. Some authors $[6,7]$ have attributed the remarkable selectivity to a property of the narrow zeolite pores, but electronic effects may play a role [8], and particle size effects should not be ruled out.

The goal of this research was to characterize the structure of a $\mathrm{Pt} / \mathrm{L}$ zeolite having virtually all the metal confined to the intracrystalline space. The characterization techniques are extended X-ray absorption fine structure (EXAFS) spectroscopy, transmission electron microscopy (TEM), and hydrogen chemisorption.

\section{Experimental and analytical methods}

\section{PREPARATION OF CATALYST}

The KL zeolite was obtained from Linde and found by analysis to contain 6.4 $\mathrm{wt} \% \mathrm{Al}, 11.3 \mathrm{wt} \% \mathrm{~K}$, and $0.04 \mathrm{wt} \% \mathrm{Na}$. The zeolite was ion exchanged with excess aqueous barium nitrate, washed, and dried at $400 \mathrm{~K}$. The resulting Ba-exchanged zeolite was analyzed and found to contain $7.4 \mathrm{wt} \% \mathrm{Ba}$. The BaKL zeolite was impregnated with tetraamine platinum (II) nitrate to give a sample containing $1.2 \mathrm{wt} \%$ Pt. Prior to any further experiments the sample was reduced at $773 \mathrm{~K}$ for $1 \mathrm{~h}$.

\section{TRANSMISSION ELECTRON MICROSCOPY}

The electron microscope was a Philips 400T TEM operated at $120 \mathrm{kV}$ with magnifications from 28,000 to 175,000 . Further magnification was obtained by enlargement of the negatives. The Energy Dispersive X-ray (EDX) spectra were obtained with a Tracor Northern 5500 energy dispersive X-ray spectrometer. The prereduced samples were ground to a fine powder, embedded in LR white resin, and sectioned with an ultramicrotome. The thin sections were mounted on copper grids and lightly coated with carbon.

\section{HYDROGEN CHEMISORPTION}

Volumetric hydrogen chemisorption measurements were performed with a conventional glass system at $298 \mathrm{~K}$. Hydrogen was dried by passage over silica. Before measurement of a chemisorption isotherm, the catalyst sample was treated in flowing hydrogen, it was heated at a rate of $5 \mathrm{~K} / \mathrm{min}$ to $773 \mathrm{~K}$ and held at that temperature for $1 \mathrm{~h}$. The sample was then evacuated $\left(10^{-2} \mathrm{~Pa}\right)$ for $1 \mathrm{~h}$ at $773 \mathrm{~K}$. After hydrogen admission at $473 \mathrm{~K}$ (hydrogen partial pressure $=93 \mathrm{kPa}$ ), desorp- 
tion isotherms were measured at room temperature. The total number of chemisorbed $\mathrm{H}$ atoms was obtained by extrapolating the linear high-pressure part of the isotherm to zero pressure. Details are as given elsewhere [9].

\section{EXAFS DATA COLLECTION}

The sample was characterized by EXAFS spectroscopy at the Synchrotron Radiation. Source in Daresbury, U.K., Wiggler Station 9.2, using a Si (220) double crystal monochromator. The storage ring was operated with an electron energy of $2 \mathrm{GeV}$ and a current between 120 and $250 \mathrm{~mA}$. At the Pt $\mathrm{L}_{\mathrm{III}}$ edge $(11564 \mathrm{eV})$, the estimated resolution was $3 \mathrm{eV}$. The monochromator was detuned to $50 \%$ intensity to avoid the effects of higher harmonics present in the X-ray beam. The measurements were done in the transmission mode. The decrease low- and high-frequency noise as much as possible, each data point was counted for $1 \mathrm{~s}$ and 6 scans were averaged.

The sample was pressed into a self-supporting wafer (calculated to have an absorbance of 2.5) and placed in a controlled-atmosphere cell [10], with the sample handled in the absence of air. The sample was heated at a rate of 5 $\mathrm{K} / \mathrm{min}$ to $723 \mathrm{~K}$ in flowing, purified, and dried hydrogen at atmospheric pressure. The sample was held at this temperature for one additional hour, then cooled to room temperature as hydrogen flow was continued. The measurements were done with the sample at liquid-nitrogen temperature in the presence of hydrogen at atmospheric pressure.

EXAFS DATA ANALYSIS

Standard procedures were used to extract the EXAFS functions from the absorption spectra [11,12]. Experimentally determined reference data for the phase shifts and backscattering amplitudes were obtained from EXAFS measurements of platinum foil and $\mathrm{Na}_{2} \mathrm{Pt}(\mathrm{OH})_{6}$ [13]. The computer software provided by Mustre de Leon and Rehr [14] was used to calculate the phase shift and backscattering amplitude of the Pt-Ba absorber-backscatterer pair. To determine reliably the parameters characterizing the high $-Z$ (Pt and $\mathrm{Ba}$ ) and low $-Z(\mathrm{O})$ contributions, multiple-shell fitting in $k$ space and in $r$ space was done, with application of $k^{1}$ and $k^{3}$ weighing [13]. Further optimization of the fit was done by applying the difference file technique and phase- and amplitude-corrected Fourier transforms $[12,13]$.

\section{Results and discussion}

A representative electron micrograph of the $\mathrm{L}$ zeolite-supported platinum catalyst is shown in fig. 1 . The micrographs show zeolite particles with rounded 


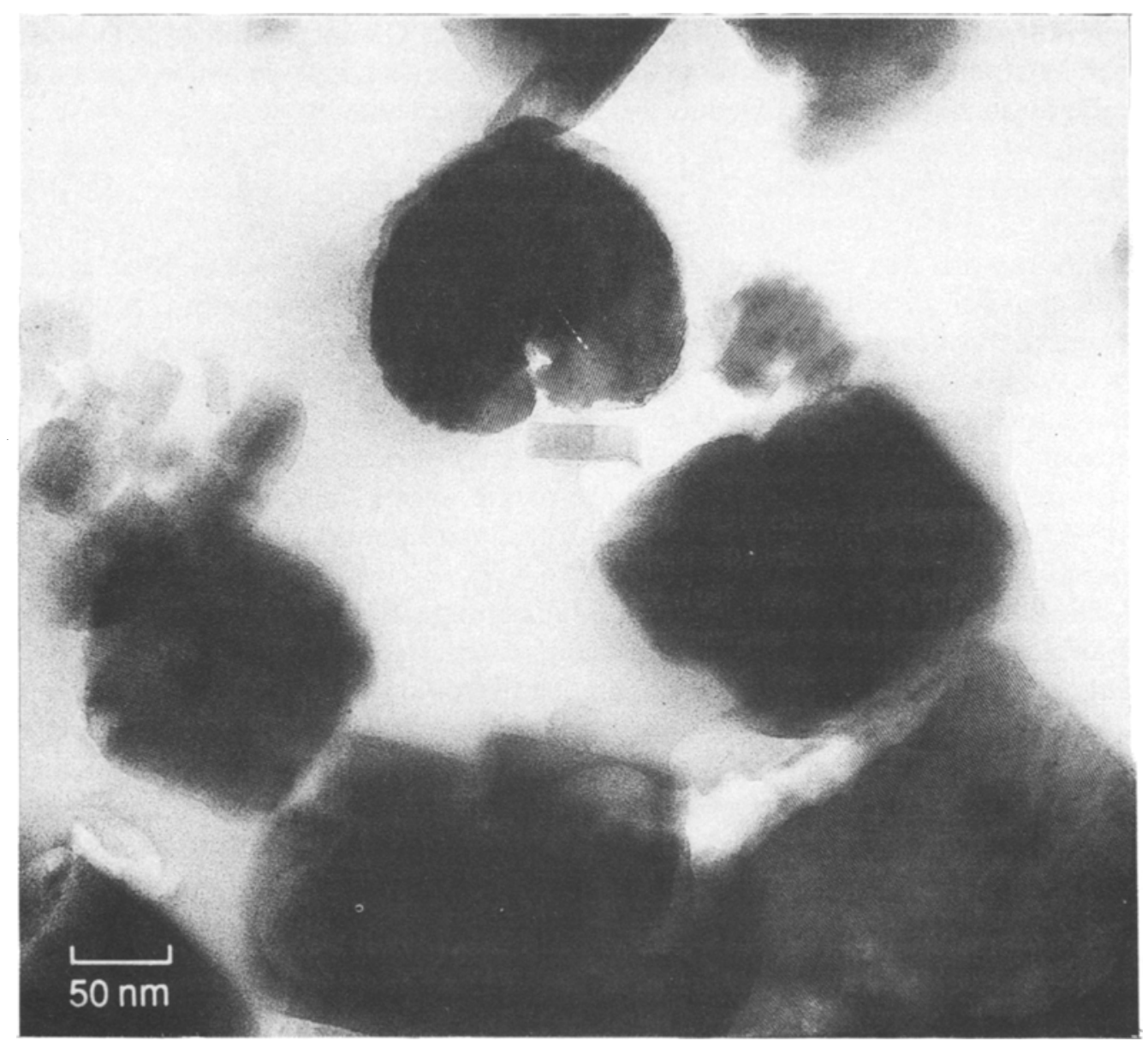

Fig. 1. Representative transmission electron micrograph of a $1.2 \mathrm{wt} \% \mathrm{Pt} / \mathrm{BaKL}$ after a reducing pretreatment of the platinum salt. The micrograph shows very small Pt clusters. The lattice images of the zeolite are also evident.

or rectangular cross sections. No large Pt particles were present. In the particles with rectangular cross sections lattice images are evident with spacings of $1.6 \mathrm{~nm}$ parallel to the unidirectional channels. At this magnification small platinum particles are evident between the lattice spacings. Only very few platinum particles larger than $2 \mathrm{~nm}$ are visible.

EDX spectroscopy was used to analyze several areas of this catalyst. The spectra indicate $\mathrm{Si}, \mathrm{Al}, \mathrm{K}, \mathrm{Ba}$ and $\mathrm{Pt}$, providing evidence that the platinum is present within the interior of the imaged crystallites. Since the platinum particles were not imaged by the electron microscope, we infer that the platinum particles are very small and likely well dispersed in the zeolite crystallites.

The hydrogen adsorption data are plotted in fig. 2. There was substantial fysisorption on the zeolite support (with and without Pt). Extrapolation to zero 


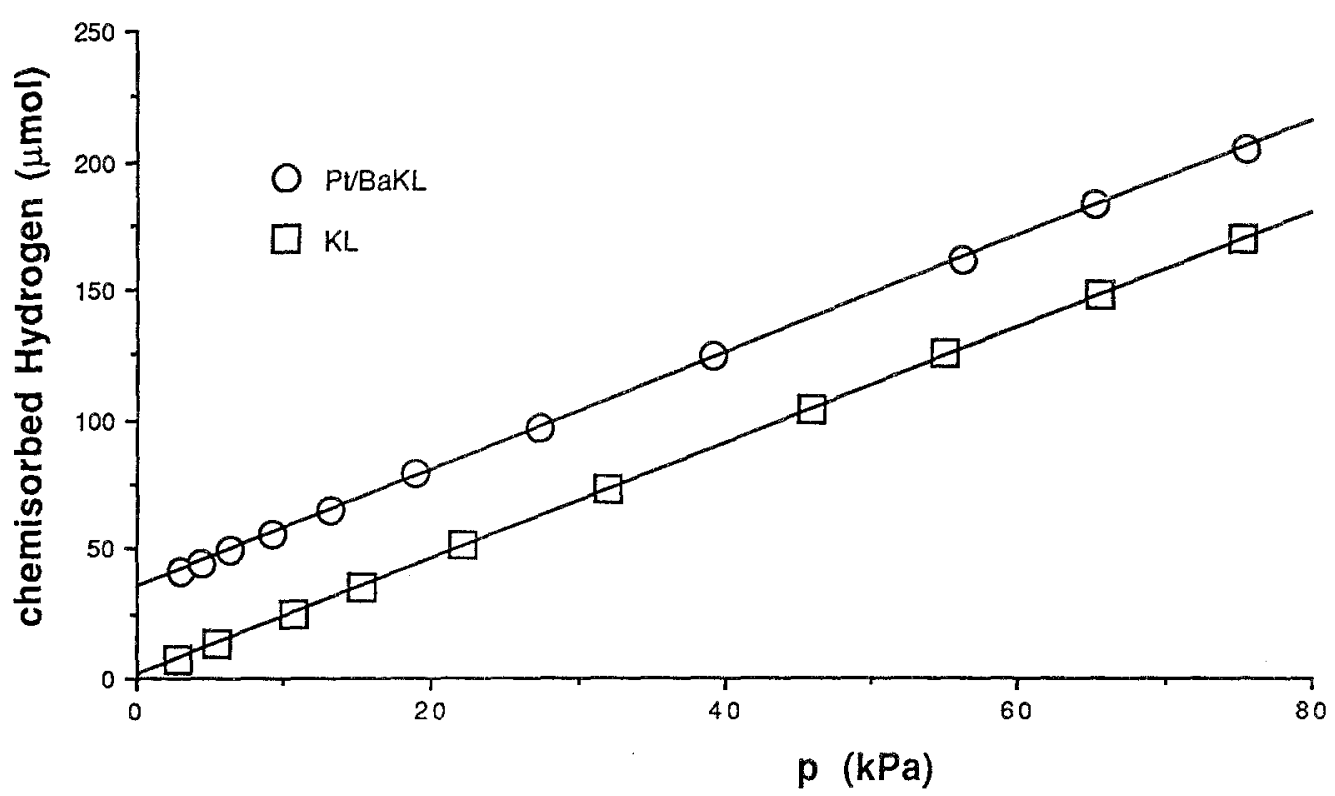

Fig. 2. Desorption isotherms for hydrogen in $\mathrm{Pt} / \mathrm{BaKL}$ zeolite $(0.867 \mathrm{~g}, 1.2 \mathrm{wt} \% \mathrm{Pt})$ and $\mathrm{KL}$ zeolite $(0.50 \mathrm{~g})$ at room temperature. Extrapolation by linear least squares fitting of the data of $\mathrm{Pt} / \mathrm{BaKL}$ gives an $\mathbf{H} / \mathrm{Pt}=1.3$.

pressure shows that adsorption on the support itself was negligible in this limit; the data of the platinum catalyst yield a value of $\mathrm{H} / \mathrm{Pt}$ equal to 1.3. This result, consistent with the microscopy data, is indicative of highly dispersed platinum.

The raw EXAFS data for the catalyst following treatment in hydrogen at 723 $\mathrm{K}$ are shown in fig. 3a. The signal to noise ratio is estimated to be 15 at $4 \AA^{-1}$. A Fourier transform of the data $\left(k^{2}\right.$ weighted, $\left.\Delta k: 2.6-12.4 \AA^{-1}\right)$ is shown in fig. $3 \mathrm{~b}$. The Pt-Pt absorber-backscatterer pair has a nonlinear phase shift and a $k$-dependent backscattering amplitude. Consequently, it is inferred that there are several peaks in the Fourier transform of a single Pt-Pt contribution $[12,13,15]$.

A $k^{1}$ weighted Fourier transform was calculated for the EXAFS data characterizing Pt foil (fig. 3c dashed line) and the catalyst (fig. 3c solid line). The magnitude of the Pt foil EXAFS function was adjusted until the first-shell Pt-Pt peak in the Fourier transform scaled with the corresponding peak derived from the Pt/BaKL EXAFS data. A comparison of the curves in fig. $3 \mathrm{c}$ clearly shows the absence of higher $\mathrm{Pt}-\mathrm{Pt}$ coordination shells in the $\mathrm{Pt} / \mathrm{BaKL}$ zeolite. This result provides yet another indication of highly dispersed platinum. Moreover, the differences in the Fourier transform $(1<R<4 \AA$, both the magnitude and the imaginary part) point to the presence of additional scatterers besides platinum. This can be seen more clearly in a Pt-Pt phase- and amplitude- corrected Fourier transform. The first Pt-Pt peak of the data characterizing Pt foil (fig. $3 \mathrm{~d}$ dashed line) appears as a single symmetrical peak. The peak located at $2.75 \AA$ in the Fourier transform of the EXAFS data characterizing the Pt/BaKL catalyst has 
an asymmetrical magnitude and imaginary part (fig. $3 \mathrm{~d}$ solid line). This is an indication that further confirms the presence of additional scatterers, most probably from the Pt-zeolite interface.

The isolation of the EXAFS contributions giving rise to peaks in the normal Fourier transform between 1 and $5 \AA$ was carried out by applying an inverse Fourier transform $(\Delta R: 1.1-3.8 \AA)$ to the data shown in fig. 3b. First-guess Pt-Pt parameters were obtained by applying a $k^{3}$-weighted fit in the range from 6 to 12 $\AA^{-1}$ to emphasize the high- $Z$ (viz. $\mathrm{Pt}-\mathrm{Pt}$ and $\mathrm{Pt}-\mathrm{Ba}$ ) contributions and deempha-
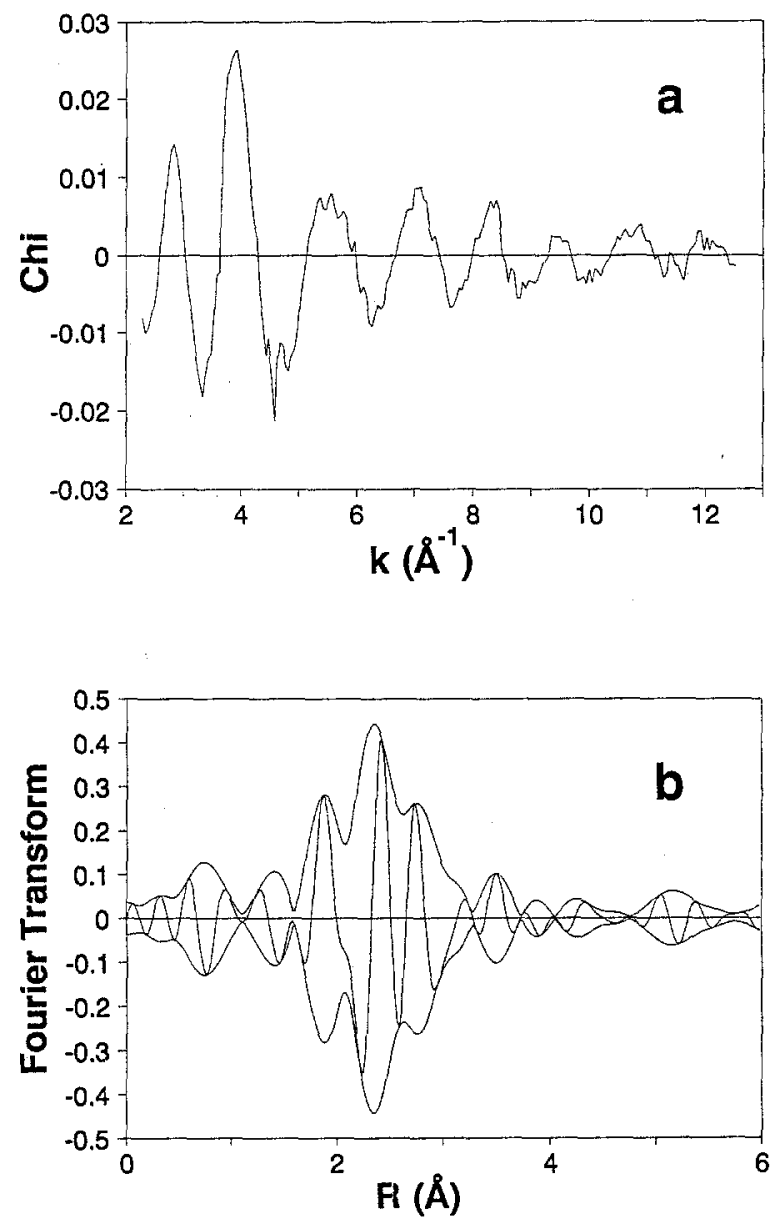

Fig. 3. a. EXAFS data for $\mathrm{Pt} / \mathrm{BaKL}$ zeolite in the presence of hydrogen at liquid nitrogen temperature; b. $k^{2}$-weighted Fourier transform of spectrum a $\left(\Delta k=2.6-12.4 \AA^{-1}\right)$; c. $k^{1}$-weighted Fourier transform of spectrum a $\left(\Delta k=2.6-12.4 \AA^{-1}\right)$ (solid line) and $k^{1}$-weighted Fourier transform of EXAFS spectrum of Pt foil $\left(\Delta k=2.7-12.6 \AA^{-1}\right)$ (dashed line) (the latter is scaled to match the amplitude of the former); d. $k^{1}$-weighted Pt-Pt phase- and amplitude-corrected Fourier transform of spectrum a $\left(\Delta k=3.0-12.4 \AA^{-1}\right)$ (solid line) and $k^{1}$-weighted Fourier transform of EXAFS spectrum of Pt foil $\left(\Delta k=3.1-12.6 \AA^{-1}\right)$ (dashed line) (the latter is scaled to match the amplitude of the former). 

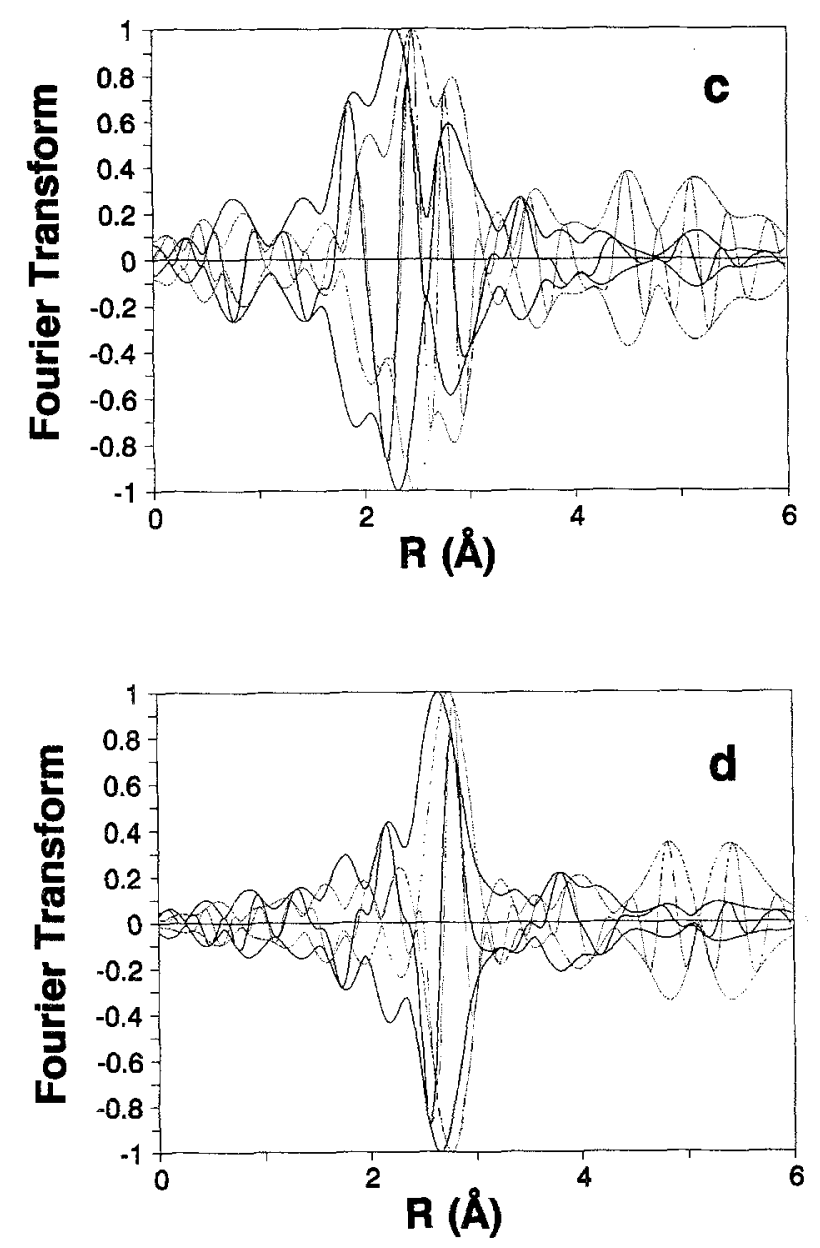

Fig. 3 (continued).

size the low- $Z$ contributions (viz. the Pt-zeolite interface). Subtraction of the metal-metal contribution resulted in an EXAFS function which was fitted with contributions characterizing the metal-zeolite interface. An iterative fitting procedure was used to optimize the fits over the whole range of $k\left(3.5-10.5 \AA^{-1}\right)$, both in $k$ space and in $r$ space. A comparison of the fit with the raw data in $k$ space and in $r$ space (with both $k^{1}$ and $k^{3}$ weighting) is shown in fig. 4. The agreement is very good.

The result of this fitting is the identification of four significant contributions (table 1), a Pt-Pt contribution at $2.75 \AA$, a $\mathrm{Pt}-\mathrm{O}$ contribution at $2.14 \AA$, a second $\mathrm{Pt}-\mathrm{O}$ contribution at $2.7 \AA$, and a $\mathrm{Pt}-\mathrm{Ba}$ contribution at $3.8 \AA$. The separate contributions to the EXAFS spectrum are shown in fig. 5, both in $k$ space and in $r$ space. The $\mathrm{Pt}-\mathrm{O}$ phase-corrected Fourier transform of the difference file obtained by subtracting the $\mathrm{Pt}-\mathrm{Pt}$ and the $\mathrm{Pt}-\mathrm{Ba}$ contributions from the primary EXAFS (i.e., the inverse Fourier transform of the raw data) is shown in fig. $5 \mathrm{~b}$. 
The presence of two $\mathrm{Pt}-\mathrm{O}$ contributions is indicated by beating oscillations in $k$ space (fig. 5a). The Pt-Ba contribution is shown in fig. 5c, and the $\mathrm{Pt}-\mathrm{Ba}$ phase-corrected Fourier transform is shown in fig. 5d. The results of fig. $5 \mathrm{c}$ (solid line) show typical high- $Z$ backscattering behavior.

The number of adjustable parameters used in the fit was 16 . The number of statistically allowable adjustable parameters calculated from the forward and the inverse Fourier transform range according to the Nyquist theorem (given in the proceedings of a workshop on standards and criteria in X-ray absorption spectroscopy [16]) is 14. Therefore the appropriateness of the parameters requires further justification. The statistical significance of the $\mathrm{Pt}-\mathrm{O}$ and $\mathrm{Pt}-\mathrm{Ba}$ contributions can be assessed by comparison of the amplitude of these EXAFS contribu-
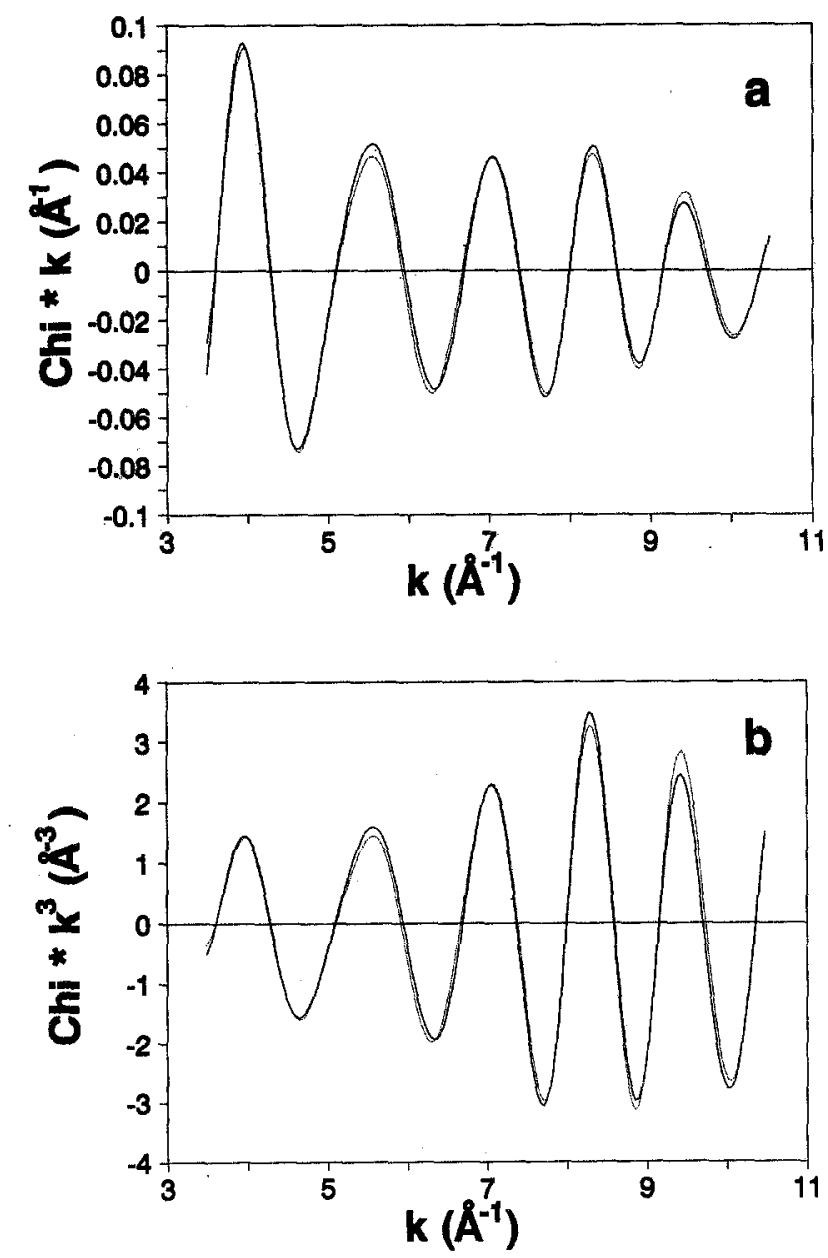

Fig. 4. a. $k^{1}$-weighted Fourier filtered EXAFS spectrum of $\mathrm{Pt} / \mathrm{BaKL}$ zeolite (fig. 3a) (solid line) and spectrum calculated with parameters of table 1 (dashed line); b. as in a, but with $k^{3}$-weighting; $c$. $k^{1}$-weighted Fourier transform of spectra in fig. 4a $\left(\Delta k=3.5-10.5 \AA^{-1}\right)$; d. as in c, but with $k^{3}$-weighting. 

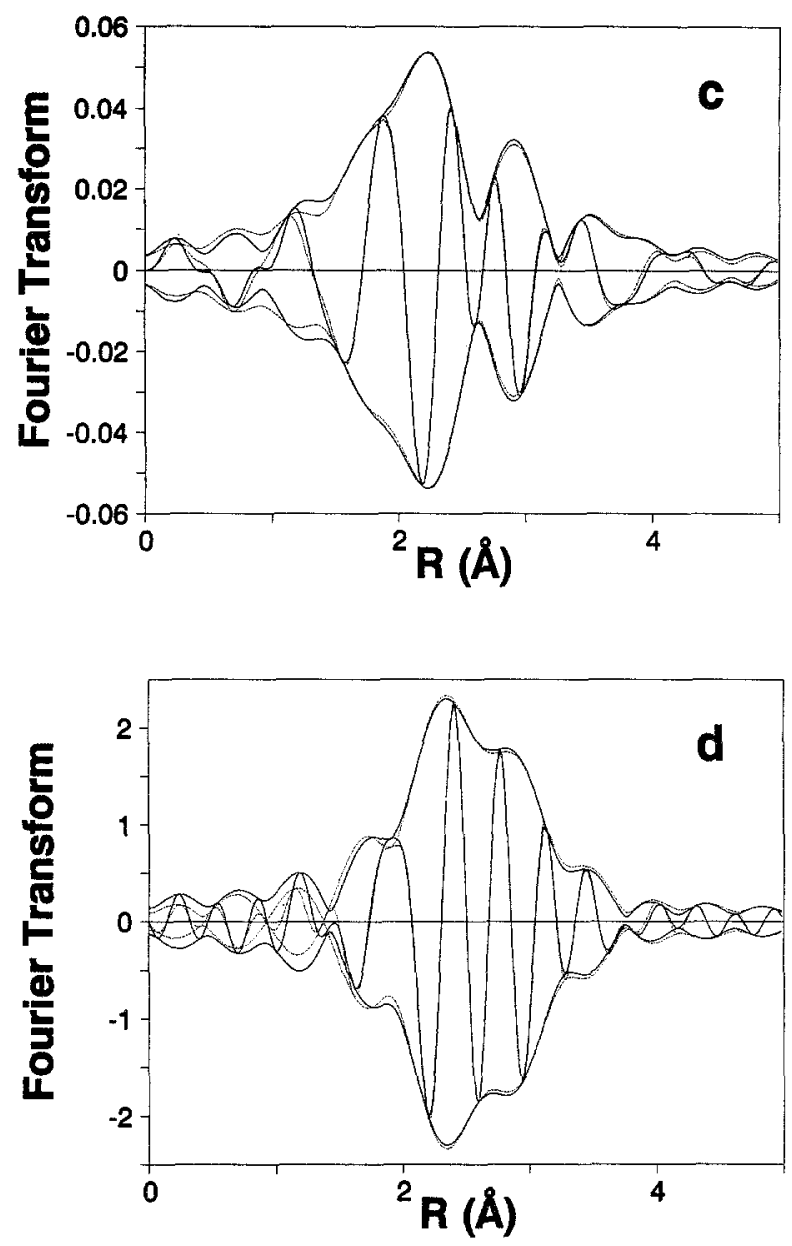

Fig. 4 (continued).

tions with the noise present in the raw data. The noise amplitude in the raw data is estimated to be $3 \times 10^{-3}$ at $k=12 \AA^{-1}$. The amplitude of the calculated Pt-O and $\mathrm{Pt}-\mathrm{Ba}$ contributions is determined to be $10 \times 10^{-3}$ and $8 \times 10^{-3}$ at $k=4.5$ $\AA^{-1}$ (fig. 5a and 5c). Since the ratios of the amplitudes of each contribution to the noise is approximately 3 , it is inferred that these contributions are statistically significant.

Table 1

Fitted contributions to the EXAFS of Pt/BaKL zeolite. Errors are given in parentheses

\begin{tabular}{lllll}
\hline Backscatterer & $N$ & $R(\AA)$ & $\Delta \sigma^{2}\left(\times 10^{-5} \AA^{-2}\right)$ & $E_{0}(\mathrm{eV})$ \\
\hline $\mathrm{Pt}$ & $3.7( \pm 0.3)$ & $2.75( \pm 0.02)$ & $32( \pm 5)$ & $1.4( \pm 0.5)$ \\
$\mathrm{O}$ & $0.6( \pm 0.1)$ & $2.14( \pm 0.03)$ & $67( \pm 10)$ & $1.8( \pm 0.5)$ \\
$\mathrm{O}$ & $1.1( \pm 0.2)$ & $2.71( \pm 0.03)$ & $95( \pm 20)$ & $2.1( \pm 1)$ \\
$\mathrm{Ba}$ & $1.4( \pm 0.2)$ & $3.76( \pm 0.05)$ & $90( \pm 20)$ & $6.6( \pm 1)$ \\
\hline
\end{tabular}


The Pt-Pt coordination number of 3.7 points to extremely small Pt clusters. If there were a bulk-like fcc packing of the $\mathrm{Pt}$ atoms in a cluster the results would imply a cluster of 5 or 6 atoms. The absence of higher $\mathrm{Pt}-\mathrm{Pt}$ coordination shells, combined with the microscopic evidence of the lack of platinum outside the zeolite and the uniqueness of the structure of the intracrystalline zeolite pores, points to a nearly unique cluster size.
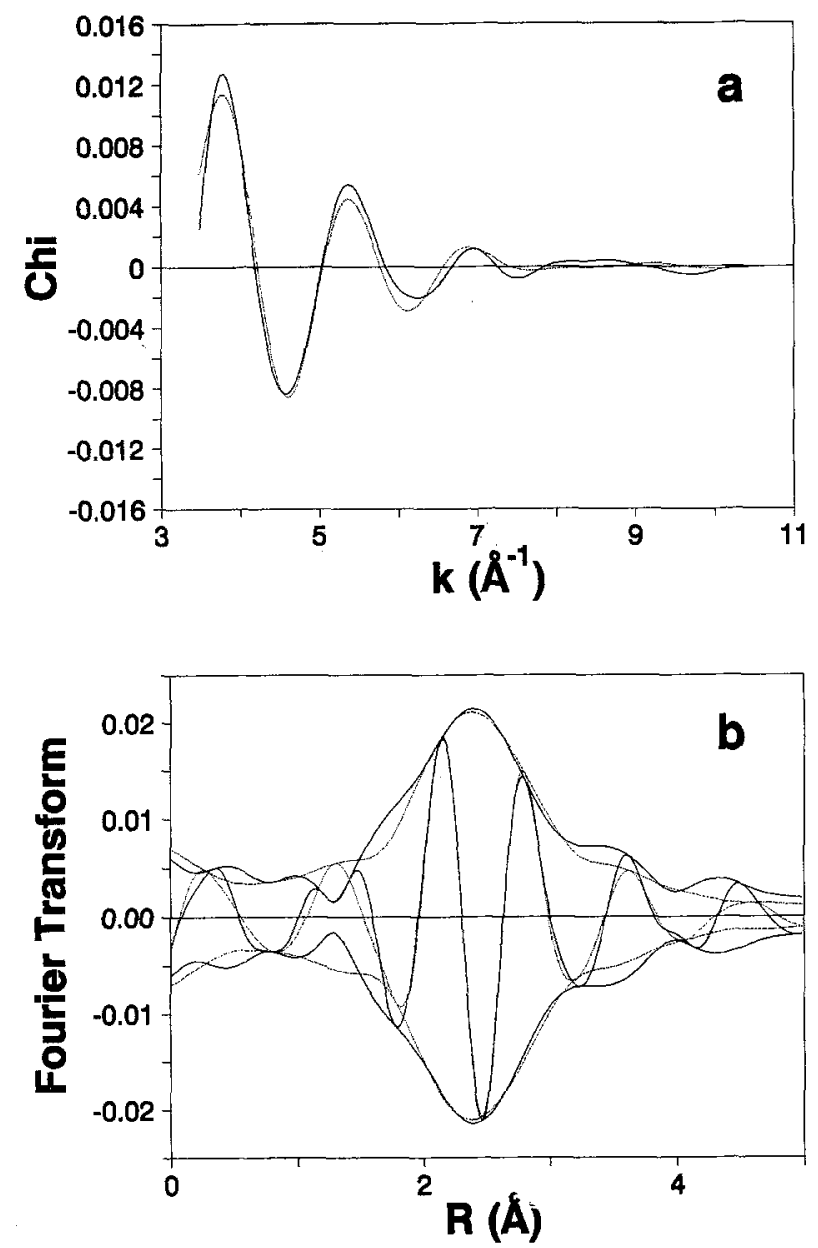

Fig. 5. a. Experimental Pt-O contribution, calculated by subtraction of the calculated Pt-Pt and $\mathrm{Pt}-\mathrm{Ba}$ contributions from the Fourier-filtered EXAFS data (fig. 4a, solid line) (solid line) and calculated Pt-O contributions (dashed line); b. Pt-O phase-corrected $k^{1}$-weighted Fourier transform of experimental spectrum a $\left(\Delta k=3.5-9.0 \AA^{-1}\right)$ and $\mathrm{Pt}-\mathrm{O}$ phase-corrected $k^{1}$-weighted Fourier transform of calculated $\mathrm{Pt}-\mathrm{O}$ contributions of spectrum a (dashed line); c. Experimental $\mathrm{Pt}-\mathrm{Ba}$ contribution, calculated by subtraction of the calculated $\mathrm{Pt}-\mathrm{Pt}$ and $\mathrm{Pt}-\mathrm{O}$ contributions from the Fourier-filtered EXAFS data (fig. 4a, solid line) (solid line) and calculated $\mathrm{Pt}-\mathrm{Ba}$ contributions (dashed line); d. Pt-Ba phase-corrected $k^{1}$-weighted Fourier transform of experimental spectrum c. $\left(\Delta k=3.5-10.5 \AA^{-1}\right)$ and $\mathrm{Pt}$-Ba phase-corrected $k^{1}$-weighted Fourier transform of calculated $\mathrm{Pt}-\mathrm{Ba}$ contribution of spectrum c. (dashed line). 


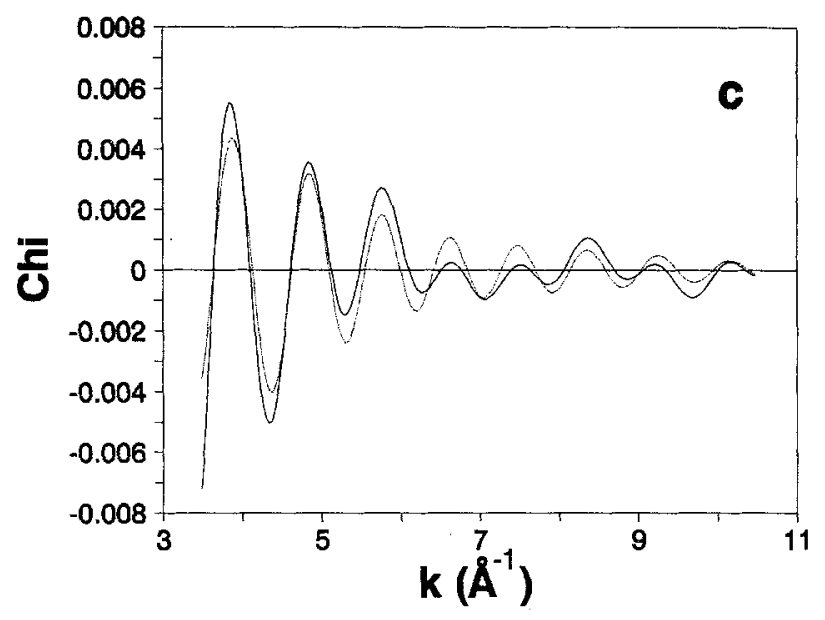

Fig. 5 (continued).

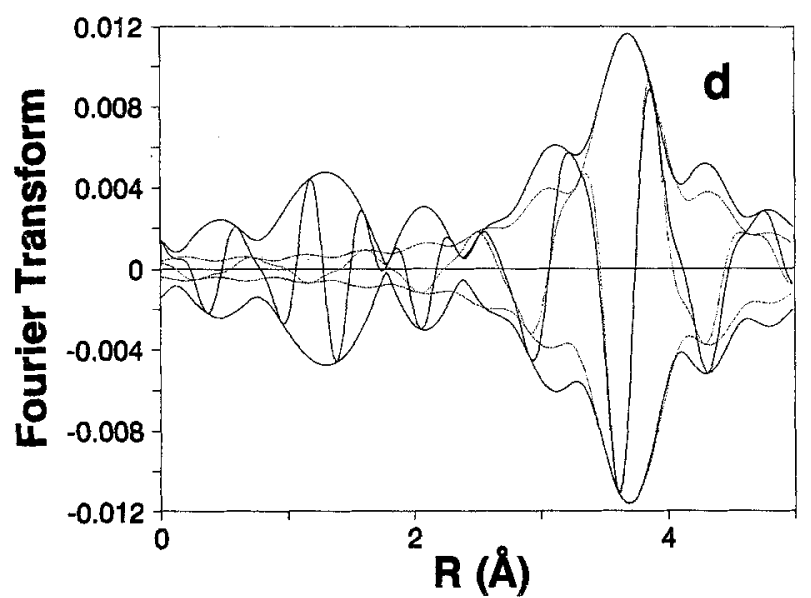

Extremely small metal particles covered with chemisorbed hydrogen show metal-metal distances equal to bulk values $[12,15]$. This type of behavior is also observed in this $\mathrm{Pt} / \mathrm{BaKL}$ sample.

The hydrogen chemisorption data confirm the high dispersion of the platinum. Extrapolation of the correlation between $\mathrm{H} / \mathrm{Pt}$ and the coordination number determined by EXAFS spectroscopy for Pt supported on $\gamma-\mathrm{Al}_{2} \mathrm{O}_{3}$, determined by $\mathrm{Kip}$ et al. [9] for a series of samples characterized by different Pt contents and temperatures of treatment in hydrogen, leads to an estimate for the coordination number of 4 for the $\mathrm{Pt}$ in zeolite $\mathrm{L}$. This estimate is in agreement with EXAFS results; it has been used to extend the correlation of Kip et al. (fig. 6).

The results of the EXAFS analysis (table 1) give evidence of two distinct $\mathrm{Pt}-\mathrm{O}$ distances. The longer of these $(2.7 \AA)$ is virtually the same as that determined earlier by EXAFS spectroscopy for highly dispersed $\mathrm{Pt} / \gamma-\mathrm{Al}_{2} \mathrm{O}_{3}$ [15]. Similar 


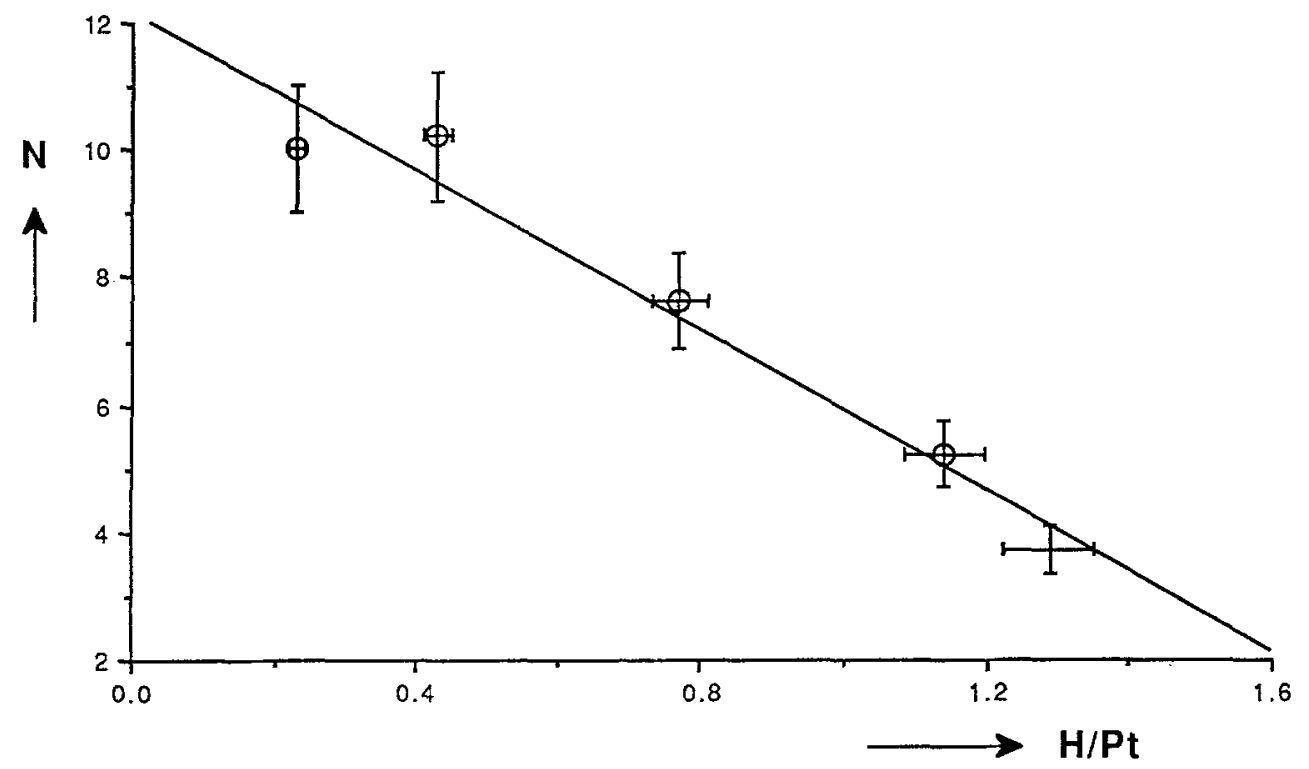

Fig. 6. Correlation of hydrogen chemisorption and first-shell Pt-Pt EXAFS coordination number data. Data represented by triangles from Kip et al. [9].

distances have been found by EXAFS spectroscopy for other highly dispersed metals [17-20].

In summary, we conclude that the $\mathrm{Pt} / \mathrm{BaKL}$ zeolite reported here is one of the most highly dispersed platinum samples and one of the most structurally uniform supported metals. The sample consequently offers a unique set of opportunities for resolving some fundamental issues in catalysis by supported metals. Specifically, further data for this catalyst are expected to provide an elucidation of the role of the narrow zeolite pores, in contrast to the size and electronic structure of the small platinum clusters (which are too small to fill the zeolite cage) in accounting for the selectivity of this catalyst [6,7]. Further, on the basis of the precise structural characterization of the sample the platinum d-band density of states can now be determined from the white line intensities from the platinum $\mathrm{L}_{\mathrm{II}}$ and $\mathrm{L}_{\mathrm{III}} \mathrm{X}$-ray absorption edges. This information is expected to allow progress towards resolution of the fundamental issue of particle size vs. electronic effects in catalysis. In addition, the EXAFS data provide evidence for a $\mathrm{Pt}-\mathrm{Ba}$ interaction. This interaction might provide experimental opportunities for assessment of the importance of polarization effects, which, on the basis of theoretical results, have recently been suggested to explain the influence of promoter ions on catalytic properties of small metal particles [21,22]. The smallness of the $\mathrm{Pt}$ clusters, combined with the uniformity of the zeolite pores, also indicates an excellent opportunity for precise characterization of the metal-support interface, which may lead to further elucidation of the nature of the interactions between metals and supports. 


\section{Acknowledgment}

This research was supported by Amoco Oil Company and the Netherlands Organization of Scientific Research (NWO). We thank Prof. J.J. Rehr for supplying the computer software for calculation of backscattering amplitudes and phase shifts.

\section{References}

[1] J.R. Bernard, Proc. 5th Int. Zeolite Conf., ed. L.V.C. Rees (Heyden, London, 1980) p. 686.

[2] P.W. Tamm, D.H. Mohr and C.R. Wilson, Catalysis 1987, ed. J.W. Ward (Elsevier, Amsterdam, 1988) p. 335.

[3] T.R. Hughes, W.C. Buss, P.W. Tamm and R.L. Jacobson, Proc. 7th Int. Zeolite Conf., eds. Y. Murakami, A. Iijima and J.W. Ward (Elsevier, Amsterdam, 1986) p. 725.

[4] C. Besoukhanova, J. Guidot, D. Barthomeuf, M. Breysse and J. Bernard, J. Chem. Soc., Faraday Trans. I, 77 (1981) 1595.

[5] S.B. Rice, J.Y. Koo, M.M. Disko and M.M.J. Treacy, Ultramicroscopy, accepted.

[6] E.G. Derouane and D.J. Vanderveken, Appl. Catal. 45 (1988) L15.

[7] S.J. Tauster and J.J. Steger, Mat. Res. Soc. Symp. Proc. 111 (1988) 419.

[8] G. Larsen and G.L. Haller, Catal. Lett. 3 (1989) 103.

[9] B.J. Kip, F.B.M. Duivenvoorden, D.C. Koningsberger and R. Prins, J. Catal. 105 (1989) 26.

[10] F.W.H. Kampers, T.M.J. Maas, J. van Grondelle, P. Brinkgreve and D.C. Koningsberger, Rev. Sci. Instr. 60 (1989) 2635.

[11] J.W. Cook Jr. and D.E. Sayers, J. Appl. Phys. 52 (1981) 5024.

[12] J.B.A.D. van Zon, D.C. Koningsberger, H.F.J. van 't Blik and D.E. Sayers, J. Chem. Phys. 12 (1985) 5742.

[13] F.W.H. Kampers, Thesis, Eindhoven University of Technology, Eindhoven, 1989.

[14] D. Lu and J.J. Rehr, Journal de Physique 47 (1987) C8-67.

[15] D.C. Koningsberger and D.E. Sayers, Solid State Ionics 16 (1985) 23.

[16] F.W. Lytle, D.E. Sayers and E.A. Stern, Physica B 158 (1989) 701.

[17] F.B.M. van Zon, G.J. Visser and D.C. Koningsberger, Proc. 9th Int. Cong. Catal., eds. M. J. Philips and M. Ternan (The Chemical Institute of Canada, Ottawa, 1988) Vol. 3, p. 1386.

[18] M.S. Tzou, B.K. Teo and W.M.H. Sachtler, J. Catal. 113 (1988) 220.

[19] K. Moller, D.C. Koningsberger and T. Bein, J. Phys. Chem. 93 (1989) 6116.

[20] J.H.A. Martens, R. Prins and D.C. Koningsberger, J. Phys. Chem. 93 (1989) 3179.

[21.] W. Ravenek, A.P.J. Jansen and R.A. van Santen, J. Phys. Chem. 93 (1989) 6445.

[22:] A.P.J. Jansen and R.A. van Santen, J. Phys. Chem., submitted. 